\title{
Effect of Whole Body Vibration on Functional Mobility in Elderly Patients
}

\author{
Jaroslav Majerník ${ }^{1 *}$, Jozef Živčák ${ }^{2}$ \\ 1 Department of Medical Informatics, Faculty of Medicine, Trieda SNP 1, 04011 Košice, Slovak Republic \\ 2 Department of Biomedical Engineering and Measurement, Faculty of Mechanical Engineering, Letná 9, 04200 Košice, Slovak Republic
}

\section{BIOGRAPHICAL NOTES}

Jaroslav Majerník, Ing. PhD. (born 1977) Head of Department of Medical Informatics at Faculty of Medicine in Košice. He received his Master's degree in the field of Electronics and Telecommunications at Technical University in Kosice, Slovakia in 2000 and Ph.D. degree in Bionics and Biomechanics in 2005. His professional and research interests include biomedical engineering and medical informatics. He is author or coauthor of seven books and more than 130 research works and projects in the fields of biomechanics and computer science. Hi is member of ESMAC, MEFANET Coordination Council and several national societies.

Jozef Živčák, Dr.h.c. prof. Ing. PhD. he is a graduate of Faculty of Mechanical Engineering, Technical University in Kosice (TUKE). Currently works as a specialized assistant at Department of Power Engineering. He actively participates in research of heat transfer, fluid flow, new technologies in area of renewable energy resources and mathematical modelling of energy processes.

\section{KEY WORDS}

Whole-body Vibration; Gait Analysis; Neurological Disorders

\section{ABSTRACT}

Whole body vibration (WBV) represents one of the most serious problems in industries. There is a discussion about effects of long-term WBV exposures on employees' health state in scientific community. However, therapeutic usage of WBV may be beneficial for various groups of patients due to the reports of enhanced muscular strength, power or even bone density. The purpose of this study was to investigate immediate response of single WBV training unit on mobility of older individuals with various neurological disorders. Twelve patients ( $67.0 \pm 3.54$ years, 4 males and 8 females) were assessed before WBV (10 min, vertical $2 \mathrm{~mm}, 30 \mathrm{~Hz}$ ) and then $1 \mathrm{~min}$ afterwards. Individual changes in gait kinematics were analyzed and the results indicated positive effects of WBV. Kinematical gait parameters were more symmetric considering right and left side. Depending on the severity of patient's disease these changes were more or less significant. The improvements in gait kinematics after WBV convinced us that this technique can be carefully used in patients' therapy and it may be used together with individually planed rehabilitation processes to bring more satisfying results.

\section{Introduction}

Ageing of the population brings growing demands on social and health care sys- 
tems due to the increased risks of various chronic diseases in older individuals. Health related quality of human life and loss of independence can be also affected by natural weakening of human body and its functional systems. This leads to more frequent falls and consecutive health and mobility problems [1-3]. Here, the disorders like sensory loss, vestibular dysfunction, impaired vision, muscular weakness, bone rarefaction or gait disorders are multifactorial disorders that contribute to vulnerability and frailty of elderly persons. Moreover, elderly falls are usually reasons for additional medical interventions. Motor impairment syndromes are also associated with neurological disorders [4]. This group of clinically heterogeneous diseases causes severe problems in coordination, gait, balance, voluntary muscle control, power and strength $[5,6]$.

Strategies to prevent negative consequences of functional mobility diseases have to be widely discussed, assessed and applied in health care of elderly patients. Such strategies include also rehabilitation techniques and physical exercises. Here, due to the published results the whole body vibration (WBV) can be considered as reliable and effective tool in rehabilitation and sport medicine $[7,8]$. The studies realized during past decade indicate that WBV may increase muscle strength, neuromuscular function, bone mass and mineral density [911], can be useful in improving physical capacity, cardiorespiratory functions, hormonal production, proprioception, and balance [12-14]. Despite of WBV positive effects presented in almost all related research studies, the authors interpret their results with caution. Also, the underlying mechanisms by which WBV enhance neuromuscular performance vary between studies and are still unclear. Inconsistency in presented results is caused by various training protocols and heterogeneity in study designs.

There are various vibrating platforms available as commercial products used by many wellness centers and rehabilitation clinics. The main differences are in the type of vibration stimulation, frequency range, and amplitude of vibration [15 - 21]. Most of the vibrating platforms vibrate sinusoidally. The subjects stand on the platform which oscillates only vertically or side alternating. Other types of vibrating devices uses two separate platforms to produce vibrations for each foot independently. While commercial usage promotes WBV as attrac- tive and effective alternative to resistance training, the therapeutic applications should carefully consider duration of WBV exposure, main vibration characteristics as well as their effects on neuromuscular system respecting patients' physical capabilities. The rest periods between vibration trainings may also play a significant role in final WBV effects. We hypothesize that the WBV may stimulate muscle activation in elderly patient with neurological disorders and that application of WBV will result in improvement of quality of their gait. Therefore, the purpose of this study was to investigate whether the single WBV session has any positive effects on gait kinematics.

\subsection{Participants}

\section{Methods}

A group of twelve elderly patients (age $67.0 \pm$ 3.54 years, 4 males, 8 females) with various neurological disorders were included in the study. The inclusion criteria were ambulatory patients able to walk independently, had no cardiovascular disease or epilepsy, and had no prior experience in WBV training. All patients were informed about the WBV training, tests to be realized and possible risks and benefits of the research. Prior to participation they gave written informed consent approved together with the study design by the local Ethics Committee. All participants attended a familiarization session before the study was realized. No other physical treatment or intervention was realized at least 24 hour before WBV session. The anthropometric measures were also taken and registered in patients' experimental protocols. As for the aim of the study, the anthropometric characteristics of lower extremities were preferred, including thigh length (right: $44.83 \pm 2.33 \mathrm{~cm}$, left: $44.33 \pm 2.19 \mathrm{~cm}$ ), calf length (right: $41.92 \pm 3.96 \mathrm{~cm}$, left: $41.58 \pm 4.08 \mathrm{~cm}$ ) and foot length (right: $25.71 \pm 2.94 \mathrm{~cm}$, left: $25.88 \pm$ $2.66 \mathrm{~cm})$

\subsection{Study Design}

The experimental protocol was designed to discover potential immediate response of a single WBV training unit to the quality of gait kinematics in elderly patients. Training sessions were supervised by rehabilitation specialist and measurements as well as WBV sessions were conducted in the same thermally neutral room intended for physical training. All subjects did not engage in 
any therapeutic or rehabilitation procedures before testing. The training session started with physical examination and short warming-up walk. Then, the patient's gait was captured and analyzed before WBV exposure. Participants were asked to walk at their natural waking speed along the $6 \mathrm{~m}$ long path. After reaching the end point of the path, they were asked to turn back $\left(180^{\circ}\right)$, i.e. change the direction of gait, and to walk back to the starting point.

Then, they turned back again and walked to the end point of the path, where the last turn back was realized and the patients finished walking in starting point of the path. In that sense, the subjects passed the length of walking path four times. WBV session followed one minute after this control gait was realized and captured. Here, each participant stood in static position on the vibration platform (VibroGym inSPORTline) with no shoes and socks and holding on the device handle. Erected posture with slightly bended knees was required during vibration test. The patients were asked to stop the training in the case of any pain responses to vibration. Duration of one WBV training unit was set to $10 \mathrm{~min}$. Sinusoidal vertical vibration frequency was $30 \mathrm{~Hz}$ with amplitude of $2 \mathrm{~mm}$. 1 min rest interval followed after this WBV exposure. Then, the patient's gait was captured and analyzed again.

\subsection{Outcome Parameters}

Gait assessment was performed using our marker-free motion analysis system MAFRAN. Here, the patient's gait in sagittal plane is captured using any commercial video camera. Then, the raw record is used in the system to reconstruct motion trajectories of human body anatomical landmarks, i.e. the trajectories of all lower extremity joints and adjacent segments. These trajectories are consequently used to calculate other kinematical parameters for detailed description of patient's gait. Here analyzed parameters include positions, velocities and accelerations of individual joints, hip flexion/ extension, knee flexion/extension, and ankle plantar/dorsal flexion angles, gait cycle length, gait cycle time, gait cycle velocity, cadence (cycles per minute), stance phase and swing phase of the gait cycle.

\subsection{Statistics}

All the parameters were analyzed individually within the subject and then within the group of here included patients. The kinematical characteristics of the patients were evaluated as differences between right and left side. The hypothesis was based on assumption that these differences should be smaller after WBV training comparing values obtained before WBV training. Otherwise, the WBV will probably have no immediate benefits for gait kinematics. Statistical methods included descriptive statistics and Student's paired t-test and were used to ascertain specific and significant differences. The significance level was set to $\mathrm{P}<0.05$.

\section{Results}

WBV session was well accepted by all in the study included elderly patients. No one felt any pain or expressed any problems during WBV exposure. A first analysis was performed with anatomical joint angles of lower extremities in sagittal plane. Individually, no of the patients had the same curves of all tree joints comparing before and after WBV values. At least on joint was changed either in positive
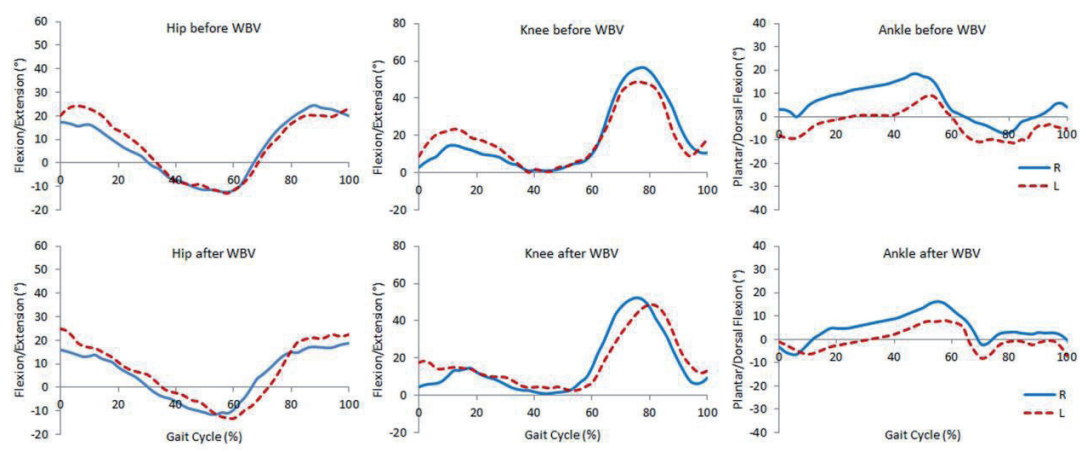

Fig. 1: Anatomical joint angles in 65 years old male patient with right hemiparesis before and after WBV exposure (solid line - right leg, dashed line-left leg). 
or negative direction. An example of anatomical joint angles changes in 65 years old male patient with right hemiparesis is shown in figure 1 .

A paired t-test determined that the mean decrease of differences $(M=0.47, S D=4,29, N=51)$ was not significantly greater than zero, $\mathrm{t}(50)=0.78$, two-tail $p=0.441$ ( $95 \% C L=1.208$ ), providing evidence that the WBV was not effective in reduction of differences between right and left hip flexion/ extension angle. Knee flexion/extension angle of the same patient showed that the mean differences between right and left side before and after WBV were decreased, but the mean decrease of differences ( $M=0.54, S D=8,207, N=51)$ was not significantly greater than zero, $\mathrm{t}(50)=0,47$, twotail $p=0.643$ (95\% CL=2.308), providing evidence that the WBV was not effective in reduction of differences between right and left knee flexion/extension angle in this patient. The mean decrease of the right and the left side differences in ankle plantar/dorsal flexion angle of the same 65 years old male patient $(M=3.79, S D=4,089, N=51)$ was significantly greater than zero, $\mathrm{t}(50)=6.63$, two-tail $p=0.000(95 \% C L=1.150)$ provided evidence that the WBV was effective in reduction of differences between right and left ankle plantar/dorsal flexion angle.

Anatomical joint angles were analyzed in all participants of this study in the same way. The summary of right and lefts side differences in anatomical joint angles in elderly patients showed that the most significant changes were registered in the ankle plantar/dorsal flexion angle $(91.67 \%)$, followed by hip flexion/extension angle (83.33\%) and knee flexion/extension angle (58.33\%). However, these significant changes include both the positive and the negative changes. The only significant positive changes were chiefly in hip flexion/extension angle $(58.33 \%)$ followed by the knee flexion/extension angle (41.67\%) and ankle plantar/dorsal flexion angle (41.67\%). Individually, there were seven patients (58.33\%) who had at least two significant positive changes of these kinematical parameters or they had no significant negative changes (subjects 1, 2, 3, 5, 8, 9 and 10). Two patients (16.67\%) had no beneficial improvements resulting from applied WBV exposure (subjects 6 and 12) and three patients (25.00\%) of the elderly patient subgroup registered worsening because of no significantly positive or only significantly negative changes (subjects 4, 7 and 11).

The second analysis was performed in spatiotemporal parameters. Here, the symmetry of all characteristics was examined and summarized. The mean differences between right and left sides and standard deviations of these parameters are listed in the table 1.

Table 1: Spatio-temporal characteristics of patients' gait obtained before and after WBV exposure $(N=12)$.

\begin{tabular}{|l|l|l|l|}
\hline \multicolumn{2}{|c}{ Pre } & Post & $\begin{array}{l}\text { Delta pre/ } \\
\text { post }\end{array}$ \\
\hline $\begin{array}{l}\text { GC length } \\
\text { (cm) }\end{array}$ & $\begin{array}{l}5.695 \pm \\
4.158\end{array}$ & $\begin{array}{l}4.718 \pm \\
4.735\end{array}$ & $\begin{array}{l}0.977 \pm \\
6,725\end{array}$ \\
\hline GC time (s) & $0.080 \pm$ & $0.080 \pm$ & $0.000 \pm$ \\
& 0.074 & 0.070 & 0.045 \\
\hline GC velocity & $0.066 \pm$ & $0.053 \pm$ & $0.013 \pm$ \\
(m/s) & 0.040 & 0.048 & 0.058 \\
\hline Cadence & $1.908 \pm$ & $2.143 \pm$ & $-0.235 \pm$ \\
(GC/min) & 1.319 & 1.380 & 1.570 \\
\hline Stance & $3.812 \pm$ & $4.158 \pm$ & $-0.347 \pm$ \\
phase (\%) & 3.441 & 4.659 & 4.797 \\
\hline Swing & $3.817 \pm$ & $4.181 \pm$ & $-0.364 \pm$ \\
phase (\%) & 3.439 & 4.642 & 4.783 \\
\hline
\end{tabular}

No of here analyzed parameters had significantly neither positive nor negative changes. Nevertheless, some of the parameters had positive and another negative tendency. The positive trends were shown in decreasing differences between right and left side in gait cycle length $(0.977 \pm 6.725)$ and velocity $(0.013 \pm 0.058)$. On the other side small increase was registered in cadence $(-0.235 \pm 1.570)$ and gait cycle stance $(-0.347 \pm 4.797)$ and swing $(-0.364 \pm 4.783)$ phase. Gait cycle time remained almost unchanged $(0.000 \pm 0.045)$.

\section{Conclusion}

In this study, the effect of single WBV training unit was tested in elderly patients with neurological disorders including multiple sclerosis, Parkinson disease, cerebral palsy and radiculoneuritis. The significant improvement was confirmed mainly in anatomical joint angles rather than in spatio-temporal parameters. As we expected, the single vibration training had only short-time effect as four of the beneficial patients were analyzed one week after the experiment and their kinematics was similar to the pre- exposure status. Using WBV training in 
patients with neurological disorders may result in benefits for kinematics of human motion, but its significance and mechanism still remain unclear and undiscovered. The usage of WBV in patients' therapy, especially in patients with neurological disorders, has to be managed by physicians to avoid serious injuries, physical harms and/or other health related damages. Based on the results we obtained, it was confirmed that there should be specified an individual WBV training and supervised functional treatment for particular patient. Further research should be realized to clarify WBV specific benefits. Also the various training approaches including standing in different static positions, sitting on chair with legs on vibrating platform or performing exercises on the platform during therapy sessions should be investigated.

\section{Acknowledge}

Results presented in this work were obtained with the support of the national grant KEGA 005UPJS-4/2012 and preparation of the grant VEGA 1/0652/14, 1/0515/13.

\section{References}

[1] Rogan, S., Hilfiker, R., Herren, K., Radlinger, L., De Bruin, E.D. (2011). Effects of whole-body vibration on postural control in elderly: A systematic review and meta-analysis. BMC Geriatric, 11, art. no. 72

[2] Sitjà-Rabert, M., Martínez-Zapata, M.J., Fort-Vanmeerhaeghe, A., Rey-Abella, F., Romero-Rodríguez, D., Bonfill, X. (2011). Whole body vibration for older persons: an open randomized, multicentre, parallel, clinical trial. BMC geriatrics, 11, p.89.

[3] Shibata, N., Ishimatsu, K., Maeda, S. (2012). Gender difference in subjective response to whole-body vibration under standing posture. International Archives of Occupational and Environmental Health, 85 (2), pp. 171-179.

[4] Pozo-Cruz, B.D., Adsuar, J.C., Parraca, J.A., Pozo-Cruz, J.D., Olivares, P.R., Gusi, N. (2012). Using whole-body vibration training in patients affected with common neurological diseases: A systematic literature review. Journal of Alternative and Complementary Medicine, 18 (1), pp. 29-41.

[5] Lau, R.W.K., Teo, T., Yu, F., Chung, R.C.K., Pang, M.Y.C. (2011). Effects of whole-body vibration on sensorimotor performance in people with parkinson disease: A systematic review. Physical Therapy, 91 (2), pp. 198-209.

[6] Pollock, R.D., Provan, S., Martin, F.C., Newham, D.J. (2011). The effects of whole body vibration on balance, joint position sense and cutaneous sensation. European Journal of
Applied Physiology, 111 (12), pp. 3069-3077.

[7] Moussavi-Najarkola, S.-A., Khavanin, A., Mirzaei, R., Salehnia M., Akbari, M. (2012). Effects of whole body vibration on outer hair cells' hearing response to distortion product otoacoustic emissions. In Vitro Cellular and Developmental Biology - Animal, 48 (5), pp. 276-283.

[8] Furness, T., Bate, N., Welsh, L., Naughton, G., Lorenzen, C. (2012). Efficacy of a whole-body vibration intervention to effect exercise tolerance and functional performance of the lower limbs of people with chronic obstructive pulmonary disease. BMC Pulmonary Medicine, 12, art. no. 71.

[9] Baumbach, S.F., Fasser, M., Polzer, H., Sieb, M., Regauer, M., Mutschler, W., Schieker, M., Blauth, M. (2013). Study protocol: The effect of whole body vibration on acute unilateral unstable lateral ankle sprain- a biphasic randomized controlled trial. BMC Musculoskeletal Disorders, p22, Article in Press.

[10] Slatkovska, L., Alibhai, S.M.H., Beyene, J., Hu, H., Demaras, A., Cheung, A.M. (2011). Effect of 12 months of whole-body vibration therapy on bone density and structure in postmenopausal women: A randomized trial. Annals of Internal Medicine, 155 (10), pp. 668-679.

[11] Cerny, M., Drska, R., Penhaker, M. (2013). Automated measurement of electrochemical sensors. IFMBE Proceedings, 39, pp. 1521-1524.

[12] Macura, D., Macurova, A. (2011). Bounded solutions of the nonlinear differential systems. International Journal of Pure and Applied Mathematics, 70 (5), pp. 755-760.

[13] Claerbout, M., Gebara, B., Ilsbroukx, S., Verschueren, S., Peers, K., Van Asch, P., Feys, P. (2012). Effects of 3 weeks' whole body vibration training on muscle strength and functional mobility in hospitalized persons with multiple sclerosis. Multiple Sclerosis, 18 (4), pp. 498-505.

[14] Artero, E.G., Espada-Fuentes, J.C., Argüelles-Cienfuegos, J., Román, A., Gómez-López, P.J., Gutiérrez, A. (2012). Effect of whole-body vibration and resistance training on knee extensors muscular performance. European Journal of Applied Physiology, 112 (4), pp. 1371-1378.

[15] Penhaker, M., Stankus, M., Prauzek, M., Adamec, O., Peterek, T., Cerny, M., Kasik, V. (2012). Advanced experimental medical diagnostic system design and realization. Elektronika ir Elektrotechnika, (1), pp. 89-94.

[16] Milanese, C., Piscitelli, F., Simoni, C., Pugliarello, R., Zancanaro, C. (2012). Effects of whole-body vibration with or without localized radiofrequency on anthropometry, body composition, and motor performance in young nonobese women. Journal of Alternative and Complementary Medicine, 18 (1), pp. 69-75.

[17] Petrovová, E., Maženský, D., Luptáková, L., Holovská, K., Špaleková, E., Massanyi, P., Haladová, E., Tóth, T.: Alterations 
in the rabbit lymphoid tissue after bendiocarb administration, Journal of Environmental Science and Health : Part B : Pesticides, Food Contaminants, and Agricultural Wastes. Vol. 45, no. 7, 2010, p. 719-728., ISSN 0360-1234

[18] Michalíková, M., Tóth, T., Rajtúková, V.: Postupy využivané pri hodnotení stability ludského tela $v$ stoji, Produktivita a inovácie. Roč. 13, č. 6, 2012, s. 24-25., ISSN 1335-5961

[19] Harachová, D., Tóth, T.: Deformation analysis and modification in the profile the harmonic drive, Technológ. Roč. 5, č. 4, 2013, s. 63-66., ISSN 1337-8996

[20] Lacková, M. - Tóth, T., Michalíková, M., Capík, I. - Bednárčíková, L.: Bond traction measurement of orthodotic brackets using orthodontic adhesives and composite filling material, Physiological Research. Vol. 59, no. 5, 2010, p. 39P-39P., ISSN 0862-8408

[21] Tóth, T.: Návrh zariadenia na meranie intra-abdominálneho tlaku, TU Košice, 2009 